\title{
Study on the Talent Flexible Training Mode of Bioinformatics Direction in Agricultural Information
}

\author{
Henghua Shi ${ }^{1, a^{*}}$ and $\mathrm{Xin} \mathrm{Xu}^{2, \mathrm{~b}}$ \\ ${ }^{1}$ School of Computer and Information Engineering, Beijing University of Agriculture, China \\ ${ }^{2}$ Communication Technology Bureau, Xinhua News Agency, China \\ ahenghuashi@163.com, byouges@163.com
}

Keywords: Bioinformatics; Agricultural information; Flexible training mode; Course system

\begin{abstract}
The talent flexible training is a new type of personnel training mode. Bioinformatics direction is one of most important part of agricultural information. In this paper, we introduce the content of bioinformatics and analysis the meaning of the agricultural information talent flexible training mode, and make the course system and teaching model of the flexibility and balance of bioinformatics direction in the agricultural information.
\end{abstract}

\section{Introduction}

The characteristic of agricultural information is integrated information science and agricultural knowledge, the goal is to develop agricultural information technology research, application, and management of the complex high-level application of specialized personnel. Bioinformatics direction is one of most important part of agricultural information, and is an interdisciplinary field that develops methods and software tools for understanding biological data. As an interdisciplinary field of science, bioinformatics combines computer science, statistics, mathematics, and engineering to analyze and interpret biological data.

Now, many scientific research institutions, universities and company need more and more bioinformatics talents to research and teaching. Therefore, bioinformatics talent training becomes more pressing thing. In this paper, we analysis the meaning of the agricultural information talent flexible training mode, and make the course system and teaching model of the flexibility and balance of bioinformatics direction in the agricultural information.

\section{The Meaning of the Agricultural Information Talent Flexible Training Mode}

The talent flexible training mode mainly based on social economy, science and technology requirement, training students for the future development of economy and science and technology of dynamic adaptation ability, in the teaching course system, teaching management has a larger group, selective and sustainable development.

The agricultural information talents training include three aspects: teaching management, training process and agricultural information talent's skills such as research, development and comprehensive. The flexible training mode is the flexibility and balance design of the three aspects. With building the suitable agricultural information talents training platform, we can optimize knowledge structure, reflect its subjectivity and individuality, and construct the open, multi role flexible teachings.

\section{Bioinformatics Direction in Agricultural Information}

Different scientific research institutions and universities have different training direction in agricultural information. Bioinformatics direction is one of most important part of agricultural information, and bioinformatics has become an important part of many areas of biology. The term bioinformatics did not mean what it means today. Paulien Hogeweg and Ben Hesper coined it in 1970 to refer to the study of information processes in biotic systems.[1][2][3] This definition placed bioinformatics as a field 
parallel to biophysics or biochemistry. For the agriculture university making agriculture and biology as the main training direction, bioinformatics become a main training direction in agricultural information.

In experimental molecular biology, bioinformatics techniques such as image and signal processing allow extraction of useful results from large amounts of raw data. In the field of genetics and genomics, it aids in sequencing and annotating genomes and their observed mutations. It plays a role in the text mining of biological literature and the development of biological and gene anthologies to organize and query biological data. It also plays a role in the analysis of gene and protein expression and regulation. Bioinformatics tools aid in the comparison of genetic and genomic data and more generally in the understanding of evolutionary aspects of molecular biology. At a more integrative level, it helps analyze and catalogue the biological pathways and networks that are an important part of systems biology. In structural biology, it aids in the simulation and modeling of DNA [4], RNA [5], proteins [6] as well as bimolecular interactions [7] [8] [9].

The talent flexible training mode of bioinformatics direction in the agricultural information includes making the course system and teaching model of the flexibility and balance.

The Course System. For bioinformatics direction in the agricultural information, the course system not only includes all core courses of bioinformatics, but also includes some main courses of agricultural information such as Agricultural Information Introduction, Agricultural Information Acquisition and Processing. The core courses of bioinformatics are General Biology, Biochemistry, Molecular Biology, Genetics, Computational Biology, Genomics, Proteomics, Bioinformatics Software and Database, Linux, Perl programming, et al. Then, Bioinformatics direction in the agricultural information needs many computer sciences and technology courses such Operating System Principle, Algorithm Analysis, Program Design, Database Systems, et al.

On the other way, the course system can be recognized as Table 1.

Table 1 The course system of bioinformatics direction in the agricultural information

\begin{tabular}{lrll}
\hline \multicolumn{2}{c}{ Agricultural Relevant Course } & Biology Relevant Course & Computer Relevant Course \\
\hline $\begin{array}{l}\text { Agricultural } \\
\text { Introduction }\end{array}$ & Information & General Biology & Operating System Principle \\
$\begin{array}{l}\text { Agricultural } \\
\text { Acquisition and Processing }\end{array}$ & Information & Biochemistry & Algorithm Analysis \\
$\ldots \ldots$ & & \\
& Molecular Biology & Program Design \\
& Genetics & Database Systems \\
& Computational Biology & $\ldots . .$. \\
& Genomics & \\
& Proteomics & \\
& $\ldots \ldots$ & \\
& & \\
& &
\end{tabular}

The Teaching Model. Combined with the characteristics of bioinformatics study and employment, the teaching mode should be set for and purpose; more emphasis on the practice link; in addition, graduation thesis should also be is obviously different from that of academic degree thesis, mainly for engineering. Culture needs to break through the framework of professional training, emphasis on integrity, broad and practical, theoretical and applied curriculum organically.

Module teaching is teaching resources module with excellent teaching methods and advanced teaching methods, theory teaching module needs to present biological information research in the field of life on the one hand to grasp the theory and methods of modern information technology, on the other hand to learn technology and management integration. The course content is the embodiment of the basic and advanced and scientific; at the same time, it has practical and interdisciplinary, and on this basis to highlight the guiding of the practice of the experiment. 
Then, through the practice base and the cooperative enterprises and institutions to carry out the training capacity of the training, in order to supplement the lack of practical teaching, improve their practical ability.

\section{The Flexibility and Balance of the Course System and Teaching Model [10]}

The course system and teaching model should be able to fully grasp the basic and advanced, comprehensive and cross, timely, accurately and effectively reflect the dynamic, realistic, combined with the practical needs of bioinformatics.

Attention to continue to extend the depth and width of the teaching, enhanced with the academic degree graduate student cultivation of discrimination, the implementation of flexible credit system; can increase experiment and practice teaching hours and increase the proportion of credits, and focus on teaching practice and theory of the experimental content system seamless on the ground, to ensure that will improve the students' ability of information acquisition, information processing and analysis capabilities, application ability, innovation ability, management ability and communication ability through on the whole. The flexibility and balance of the course system and teaching model is as following.

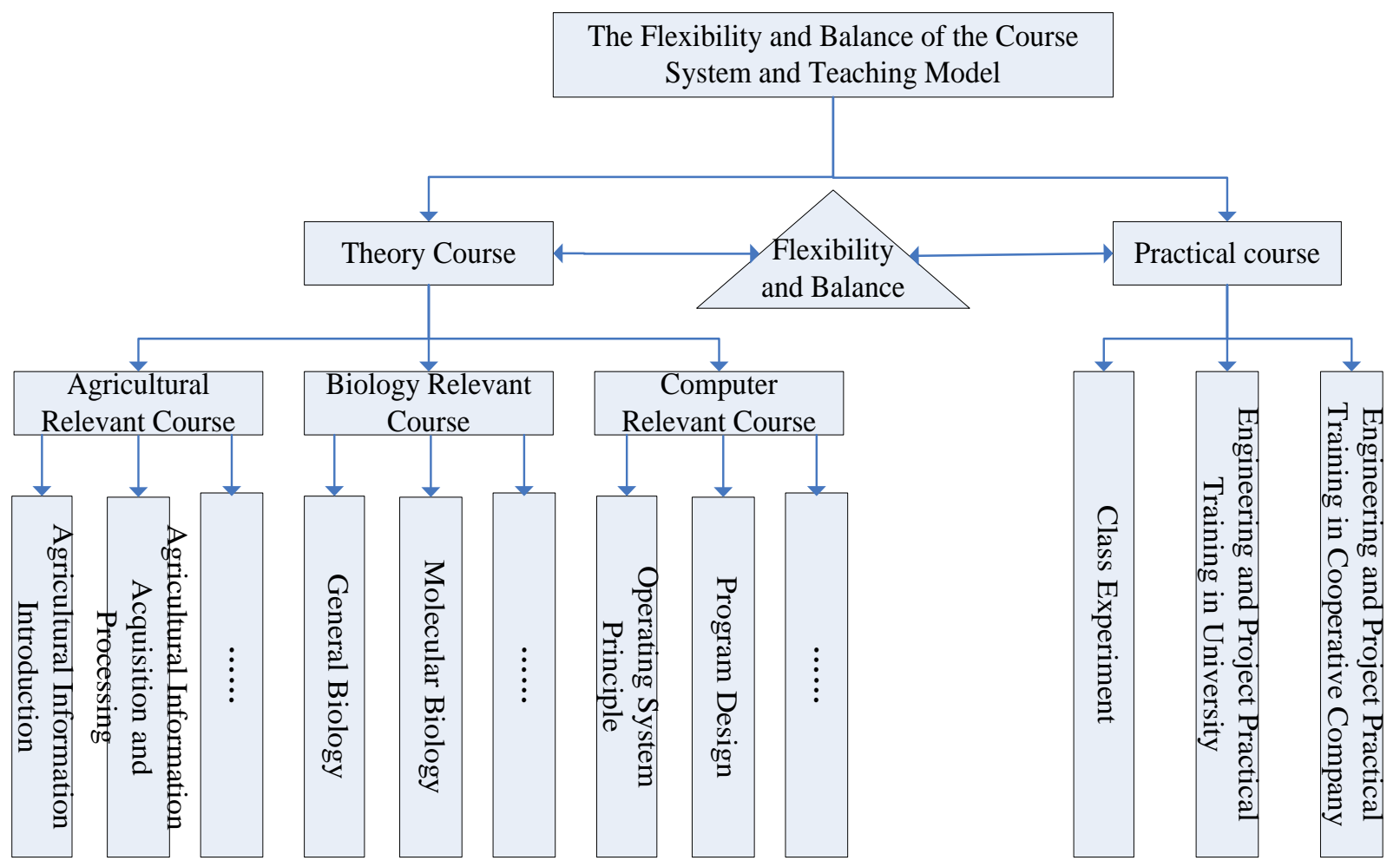

Figure 1. The flexibility and balance of the course system and teaching model

In practical operation, we can flexibly choose the theory course and practical course, and make a balance between theory and practical for different training objectives such as making science research in scientific research institutions and universities or employment in company.

\section{Summary}

Flexible training is a new type of personnel training mode. In this paper, we propose the flexibility and balance mode of the course system and teaching model for bioinformatics direction in the agricultural information. The purpose is the training of bioinformatics direction in the agricultural information becomes a flexible system. The focus on optimizing the knowledge structure, strengthening practice, balanced operation training in all aspects of the program; people-oriented, both research and practical 
ability, to improve the agricultural information technology in the field of professional master's degree of learning ability, practice ability and innovation ability.

With the study on the talent flexible training mode, we can learn bioinformatics direction in the agricultural information more easy, and research science problem with bioinformatics method more convenient in the future.

\section{Acknowledgement}

Corresponding author is Shi Henghua. The authors would like to acknowledge the supports provided by 2016 Research Fund for Academic Degree \& Graduate Education of Beijing University of Agriculture (2016YJS007), 2016 General Scientific Research Project of Beijing Municipal Education Commission (PXM2016_014207_000008).

\section{References}

[1] P. Hogeweg, D .B Searls: The Roots of Bioinformatics in Theoretical Biology. PLoS Computational Biology. 7 (3): e1002021.

[2] B. Hesper, P. Hogeweg: Bioinformatica: enwerkconcept. 1 (6) p. 28-29.

[3] P. Hogeweg: Simulating the growth of cellular forms. Simulation. 31 (3): p.90-96.

[4] YL Sim, P. Minary, M. Levitt: Modeling nucleic acids. Current Opinion in Structural Biology. Nucleic acids/Sequences and topology. 22 (3): 273-278.

[5] W. Dawson, K. Wayn, M. Maciejczyk, E. J. Jankowska, J. M. Bujnicki: Coarse-grained modeling of RNA 3D structure. Methods. Advances in RNA Structure Determination. 103: 138-156.

[6] S. Kmiecik, D. Gront, M. Kolinski, L. Wieteska, A. E. Dawid, A. Kolinski: Coarse-Grained Protein Models and Their Applications. Chemical Reviews.

[7] K. C. Wong: Computational Biology and Bioinformatics: Gene Regulation. CRC Press (Taylor \& Francis Group). ISBN 9781498724975.

[8] A. P. Joyce, C. Zhang, P. Bradley, J. J. Havranek: Structure-based modeling of protein: DNA specificity. Briefings in Functional Genomics. 14 (1): p. 39-49.

[9] E. Spiga, M. T. Degiacomi, P. M. Dal: Karabencheva-Christova, Tatyana, ed. Chapter Three New Strategies for Integrative Dynamic Modeling of Macromolecular Assembly. Biomolecular Modelling and Simulations. 96. Academic Press. p.77-111.

[10]B. Collis, J. Vingerhoets, J. Moonen: Flexibility as a key construct in European training: Experiences from the tele scopia project. British Journal of Educational Technology, 1997, 28(3): p. 199-218. 